\title{
Customized BMI and waist circumference cut-off values are needed to identify metabolic syndrome among South Koreans according to their Sasang constitutional type
}

\author{
Jun-Sang $\mathrm{Yu}^{1^{*}}$, Younghwa $\mathrm{Baek}^{2}$, Daesung Hyun ${ }^{3}$, Sei-Jin Chang ${ }^{4}$ \\ ${ }^{1}$ Department of Sasang Constitutional Medicine, College of Korean Medicine, Sangji University, Wonju, 26338, Republic \\ of Korea (hiruok@sangji.ac.kr) \\ ${ }^{2}$ Future Medicine Division, Korea Institute of Oriental Medicine, Daejeon, 34054, Republic of Korea (aori79@kiom.re.kr) \\ ${ }^{3}$ Department of Preventive Medicine and Department of Biostatistics and Computing, The Graduate School of Yonsei \\ University, Wonju, 26426, Republic of Korea (hyonds@hanmail.net) \\ ${ }^{4}$ Department of Preventive Medicine and Institute of Environmental \& Occupational Medicine, Wonju College of Medicine, \\ Yonsei University, Wonju, 26426, Republic of Korea (chang0343@yonsei.ac.kr)
}

Introduction: This study evaluated whether body mass index (BMI) and waist circumference (WC) cut-offs for predicting metabolic syndrome (MetS) were different according to Sasang constitutional type.

Methods: Data were obtained from 3,117 South Koreans (20-90 years old), and MetS was defined according to the revised NCEP-ATPIII criteria. Age-adjusted BMI and WC cut-offs were calculated according to Sasang constitutional type (Soyangin [SY], Taeeumin [TE], and Soeumin [SE]), sex, and age (men: $\geq 40$ vs. $<40$ years, women: $\geq 50$ vs. $<50$ years).

Results: The prevalences of MetS were 29.9\% ( $<40$-year-old men), 35.1\% ( $\geq 40$-year-old men), 14.8\% ( $<50$-year-old women), and $47.7 \%$ ( $\geq 50$-year-old women). The BMI $\left(\mathrm{kg} / \mathrm{m}^{2}\right)$ and WC $(\mathrm{cm})$ cut-offs for $<40$-year-old men were 25.9 and 89.9 (SY), 25.5 and 90.5 (TE), and 21.8 and 86.2 (SE). The cut-offs for $\geq 40$-year-old men were 23.1 and 88.9 (SY), 25.0 and 89.9 (TE), and 22.2 and 87.5 (SE). The BMI and WC cut-offs for <50-year-old women were 22.5 and 81.2 (SY), 25.1 and 83.0 (TE), and 21.5 and 79.8 (SE). The cut-offs for $\geq 50$-year-old women were 22.2 and 80.5 (SY), and 25.2 and 89.1 (TE), and 21.9 and 80.3 (SE).

Conclusions: The BMI and WC cut-offs for identifying MetS varied according to Sasang constitution type.

$\overline{\text { Key Words }}$ : Metabolic syndrome, Sasang constitution, Cut-off value, Body mass index, Waist circumference

\section{Introduction}

Metabolic syndrome (MetS) is defined as a cluster of several components, which are hyperglycemia, dyslipidemia (i.e., elevated triglycerides and/or low high-density lipoprotein cholesterol), hypertension, and abdominal obesity ${ }^{1,2)}$. The presence of MetS is strongly associated with the development of diabetes mellitus, cardiovascular heart disease, and increased mortality ${ }^{3}$. Thus, early-stage detection of MetS and subsequent follow-up are guided using various anthropometric indices, including body mass index (BMI), waist

\footnotetext{
- Received : 5 October 2018 - Revised : 29 November 2018 -Accepted : 29 November 2018

- Correspondence to : Jun-Sang Yu

Department of Sasang Constitutional Medicine, College of Korean Medicine, Sangji University, Wonju, Republic of Korea

Tel : +82-33-741-9203, Fax : +82-33-741-9141, E-mail : hiruok@sangji.ac.kr
} 
circumference (WC), and waist-to-hip ratio ${ }^{4), 5)}$. For example, abdominal obesity is determined using WC and is one of the most important factors for diagnosing MetS. In addition, a recent cohort study revealed that WC and BMI could help predict the development of diabetes $^{6}$. However, the cut-off values vary according to sex and race, which suggests that anthropometric indexes for identifying MetS risk should be categorized according to sex, age, and/or race.

Sasang constitutional (SC) medicine is a holistic typological constitution medicine that is tailored to the Korean population and helps individuals balance their psychological, social, and physical aspects to achieve wellness and increase longevity ${ }^{7}$. This form of medicine classifies humans into four constitutions based on their traits: Taeyangin (TY type), Soyangin (SY type), Taeeumin (TE type), and Soeumin (SE type) $)^{8)}$. Thus, it is possible that differences in clinical indexes (including body measurements) may be observed according to SC type, which may influence the assessment of health status"), and several studies have indicated that differences in pathological indexes can be observed according to SC type $\mathrm{e}^{10-12)}$.

Personalized medicine involves using accurate cut-off values to assess the patient (e.g., using WC and BMI to predict MetS) and select appropriate lifestyle modifications and/or treatments. However, it is difficult to determine individual cut-off values, which indicates that SC type could be a useful grouping, as differences in body shape, appearance, temperament, and physio-pathological symptoms can be observed according to SC type ${ }^{13)}$. For example, the TE type is characterized by unique physiological patterns, hyperactive liver function, and hypoactive lung function, which reflects a state of weak consumption and strong storage of qi and body fluid ${ }^{14)}$. In addition, the TY type is characterized by relatively large values for $\mathrm{WC}$ and $\mathrm{BMI}^{15}$. Recent studies have indicated that the TE type is an independent risk factor for various chronic disease, including diabetes, hypertension, and abdominal obesity ${ }^{16-18)}$. Therefore, the present study aimed to identify the optimal WC and BMI cut-off values for predicting MetS according to sex, age group, and SC type among South Korean people.

\section{Methods}

\section{Subjects}

This retrospective study evaluated data from the Korean Medicine Data Center (KDC), which is part of the Korea Institute of Oriental Medicine (KIOM). The KDC maintains an integrated Korean medical database that was established in 2006 and is used for research purposes because it includes nationally representative clinical questionnaire, measurement, and biological data from Korean individuals who were assessed at multiple centers. Data were collected from November 2006 to July 2013, and subjects were considered eligible if they were 20-90 years old, although subjects were excluded if they could not understand or follow the researcher's instructions, could not maintain proper posture during the measurements, if they were pregnant, or if they had body deformations (e.g., lumps or congenital malformations) ${ }^{18), 19)}$. The present study's retrospective protocol was approved by the KIOM ethics review board (I-0910/02-001).

\section{Sasang constitutional diagnosis}

The SC diagnoses were performed by an expert in $\mathrm{SC}$ medicine at each hospital. These experts had $>5$ years of experience in clinical practice, and based their decisions on the subject's physical body shape, facial appearance, temperament, and physical and/or pathological symptoms. Constitution-specific herbal formulae were administered according to the subject's SC type, and only subjects who experienced a good 
response (i.e., clinical improvement without any adverse events) after $>30$ days of treatment were included. Previous studies have used the same procedures for diagnosing SC type $\mathrm{e}^{9), 20)}$.

\section{Data collection}

Data regarding age, sex, weight, height, $\mathrm{WC}$, blood pressure, and blood test results were collected to determine if MetS was present. WC was measured at the umbilicus level during a light exhalation while the subject was standing with their arms folded in front of their chest. Blood pressure was measured at each subject's left upper arm after sufficient rest. Blood samples were obtained from the subjects' left or right brachial veins after a $\geq 12$-h fast, and were subjected to testing for fasting blood glucose, triglycerides, and high-density lipoprotein cholesterol. All laboratory tests were performed at a central laboratory to minimize test variability and error. Measurement bias was minimized by having an anthropometric measurement expert with 9 years of experience provide training to the examiners at least once per year. The KIOM monitored all data collection procedures and the examiners followed a standard operation procedure that was developed for the "Korea Constitution Multicenter Study"21).

\section{Diagnostic criteria of MetS}

MetS was defined according to the National Cholesterol Education Program Adult Treatment Panel III guidelines, which require the presence of at least 3 of 5 criteria $^{22}$. The first four criteria were (1) diastolic blood pressure of $\geq 90 \mathrm{mmHg}$, systolic blood pressure of $\geq 140 \mathrm{mmHg}$, or receiving medication to treat hypertension, (2) fasting plasma glucose of $\geq 126 \mathrm{mg} / \mathrm{dL}$ or receiving medication to treat diabetes mellitus, (3) triglycerides of $\geq 150 \mathrm{mg} / \mathrm{dL}$, and (4) high-density lipoprotein cholesterol of $<40 \mathrm{mg} / \mathrm{dL}$ for men or $<50$ $\mathrm{mg} / \mathrm{dL}$ for women. The fifth criterion was modified based on the WC cut-off values for abdominal obesity among Asian-Pacific populations $(\geq 90 \mathrm{~cm}$ for men and $\geq 80 \mathrm{~cm}$ for women $)^{23)}$, as the MetS guidelines recommend cut-off values of $>102 \mathrm{~cm}$ (40 in) for men and $>88 \mathrm{~cm}$ (35 in) for women.

\section{Statistical analysis}

There are four SC types (TY, SY, TE, and SE), although the TY type was excluded because this type is too rare to perform accurate statistical analysis. One-way analysis of variance was used to evaluate continuous variables and the chi-square test was used to compare the prevalence of MetS among the three SC types. Receiver operating characteristic (ROC) curve analysis was used to determine the BMI and WC cut-off values for predicting MetS according to sex, age, and SC type. The age groups were selected based on menopause among women $(<50 \text { years vs. } \geq 50 \text { years })^{24)}$ and andropause among men $(<40 \text { years vs. } \geq 40 \text { years })^{25}$. Data were analyzed using $\mathrm{R}$ software (version x64 3.4.1), and P-values of $<0.05$ were considered statistically significant.

\section{Results}

\section{Anthropometric and clinical variables according to SC type}

We detected significant differences in all anthropometric and clinical variables when comparing the two age groups of women, (Table 1), as well as in six of the ten variables on comparing the two age groups of men. The distribution of SC types is shown in Table 2: 1,070 subjects (34.3\%) had the SY type, 1,269 subjects $(40.7 \%)$ had the TE type, and 778 subjects $(25.0 \%)$ had the SE type. 


\section{Prevalence of MetS and metabolic components according to sex}

The prevalences of MetS were 29.9\%, 35.1\%, 14.8\%, and $47.7 \%$ among $<40$-year-old men, $\geq 40$-year-old men, $<50$-year-old women, and among $\geq 50$-year-old women, respectively (Table 3 ). When we compared the two groups of men, the only significant difference was observed in the prevalence of hyperglycemia.
However, all five components and MetS were significantly different between the two age groups of women.

\section{ROC curve analysis}

Figures 1 and 2 show the optimal cut-off values for BMI and WC according to sex and SC type. The sensitivity and specificity values for the BMI and WC cut-off values are shown in Table 4.

Table 1. Anthropometric and Clinical Variables according to Sex and Sasang Constitution Type.

\begin{tabular}{|c|c|c|c|c|c|c|}
\hline \multirow[b]{2}{*}{ Variables } & \multicolumn{2}{|c|}{$\operatorname{Men}(n=1,118)$} & \multirow[b]{2}{*}{ P-value } & \multicolumn{2}{|c|}{ Women $(n=1,999)$} & \multirow[b]{2}{*}{ P-value } \\
\hline & $\begin{array}{l}<40 \text { years } \\
(\mathrm{n}=204)\end{array}$ & $\begin{array}{c}\geq 40 \text { years } \\
(\mathrm{n}=914)\end{array}$ & & $\begin{array}{l}<50 \text { years } \\
(\mathrm{n}=919)\end{array}$ & $\begin{array}{l}\geq 50 \text { years } \\
(\mathrm{n}=1,080)\end{array}$ & \\
\hline $\mathrm{WC}, \mathrm{cm}$ & $86.92 \pm 9.12$ & $88.43 \pm 8.10$ & 0.031 & $79.36 \pm 8.44$ & $86.94 \pm 9.22$ & $<0.001$ \\
\hline BMI, $\mathrm{kg} / \mathrm{m}^{2}$ & $24.30 \pm 3.38$ & $24.20 \pm 3.02$ & 0.681 & $22.59 \pm 3.16$ & $24.19 \pm 3.15$ & $<0.001$ \\
\hline $\begin{array}{l}\text { Systolic blood pressure, } \\
\mathrm{mmHg}\end{array}$ & $121.83 \pm 14.38$ & $124.07 \pm 14.99$ & 0.047 & $113.56 \pm 14.16$ & $123.53 \pm 15.36$ & $<0.001$ \\
\hline $\begin{array}{l}\text { Diastolic blood pressure, } \\
\mathrm{mmHg}\end{array}$ & $78.97 \pm 10.56$ & $80.13 \pm 10.68$ & 0.159 & $73.53 \pm 10.12$ & $78.77 \pm 11.11$ & $<0.001$ \\
\hline Triglycerides, mg/dL & $156.65 \pm 97.12$ & $154.84 \pm 100.84$ & 0.815 & $96.69 \pm 61.19$ & $141.06 \pm 75.41$ & $<0.001$ \\
\hline HDL-cholesterol, $\mathrm{mg} / \mathrm{dL}$ & $42.50 \pm 9.36$ & $42.30 \pm 11.21$ & 0.791 & $51.65 \pm 12.80$ & $47.25 \pm 11.94$ & $<0.001$ \\
\hline $\begin{array}{l}\text { Fasting plasma glucose, } \\
\mathrm{mg} / \mathrm{dL}\end{array}$ & $93.92 \pm 20.04$ & $105.69 \pm 32.42$ & $<0.001$ & $90.87 \pm 14.52$ & $104.32 \pm 36.34$ & $<0.001$ \\
\hline Hypertension & $24(11.8 \%)$ & $362(39.6 \%)$ & $<0.001$ & $73(7.9 \%)$ & $448(41.5 \%)$ & $<0.001$ \\
\hline Diabetes mellitus & $5(2.5 \%)$ & $135(14.8 \%)$ & $<0.001$ & $22(2.4 \%)$ & $165(15.3 \%)$ & $<0.001$ \\
\hline Dyslipidemia & $23(11.3 \%)$ & $193(21.1 \%)$ & 0.002 & $48(5.2 \%)$ & $234(21.7 \%)$ & $<0.001$ \\
\hline
\end{tabular}

WC, waist circumference; BMI, body mass index; HDL: high-density lipoprotein. Data are shown as mean \pm standard deviation or number (\%).

Table 2. Distribution of Subjects according to Sex and Sasang Constitution Type

\begin{tabular}{cccccc}
\hline \multirow{2}{*}{ Sex } & Age (years) & $\begin{array}{c}\text { SY type } \\
(\mathrm{n}=1,070)\end{array}$ & $\begin{array}{c}\text { TE type } \\
(\mathrm{n}=1,269)\end{array}$ & $\begin{array}{c}\text { SE type } \\
(\mathrm{n}=778)\end{array}$ & $\begin{array}{c}\text { Total } \\
(\mathrm{n}=3,117)\end{array}$ \\
\hline \multirow{2}{*}{ Male } & $<40$ & $61(29.9 \%)$ & $83(40.7 \%)$ & $60(29.4 \%)$ & 204 \\
& $\geq 40$ & $322(35.2 \%)$ & $412(45.1 \%)$ & $180(19.7 \%)$ & 914 \\
\multirow{2}{*}{ Female } & $<50$ & $341(37.1 \%)$ & $296(32.2 \%)$ & $282(30.7 \%)$ & 919 \\
& $\geq 50$ & $346(32.0 \%)$ & $478(44.3 \%)$ & $256(23.7 \%)$ & 1,080 \\
\hline
\end{tabular}

SY: Soyangin, TE: Taeeumin, SE: Soeumin.

Table 3. Metabolic Components according to Sex and Age Group

\begin{tabular}{lcccccc}
\hline & \multicolumn{2}{c}{ Men } & \multirow{2}{*}{ P-value } & \multicolumn{2}{c}{ Women } & \multirow{2}{*}{ P-value } \\
\cline { 1 - 1 } & $<40$ years & $\geq 40$ years & & $<50$ years & $\geq 50$ years & \\
\hline Triglycerides & $87(42.6 \%)$ & $345(37.7 \%)$ & 0.222 & $106(11.5 \%)$ & $392(36.3 \%)$ & $<0.001$ \\
Hypertension & $75(36.8 \%)$ & $406(44.4 \%)$ & 0.055 & $175(19.0 \%)$ & $453(41.9 \%)$ & $<0.001$ \\
Hyperglycemia & $21(10.3 \%)$ & $245(26.8 \%)$ & $<0.001$ & $51(5.5 \%)$ & $238(22.0 \%)$ & $<0.001$ \\
Abdominal obesity & $77(37.7 \%)$ & $398(43.5 \%)$ & 0.151 & $418(45.5 \%)$ & $830(76.9 \%)$ & $<0.001$ \\
Low HDL-cholesterol & $86(42.2 \%)$ & $417(45.6 \%)$ & 0.411 & $441(48.0 \%)$ & $679(62.9 \%)$ & $<0.001$ \\
Metabolic syndrome & $61(29.9 \%)$ & $321(35.1 \%)$ & 0.180 & $136(14.8 \%)$ & $515(47.7 \%)$ & $<0.001$ \\
\hline
\end{tabular}

HDL: high-density lipoprotein. Data are shown as number (\%). 


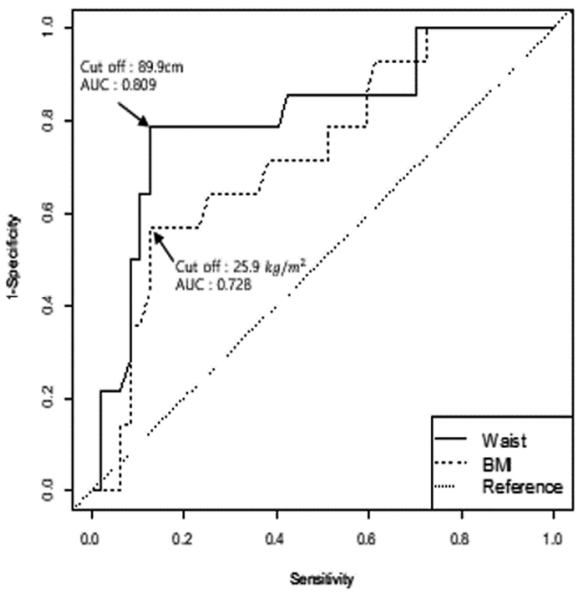

(a) SY type (<40 years)

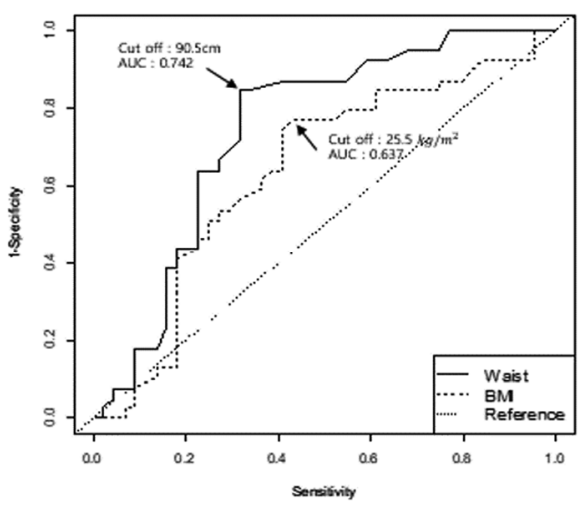

(c) TE type (<40 years)

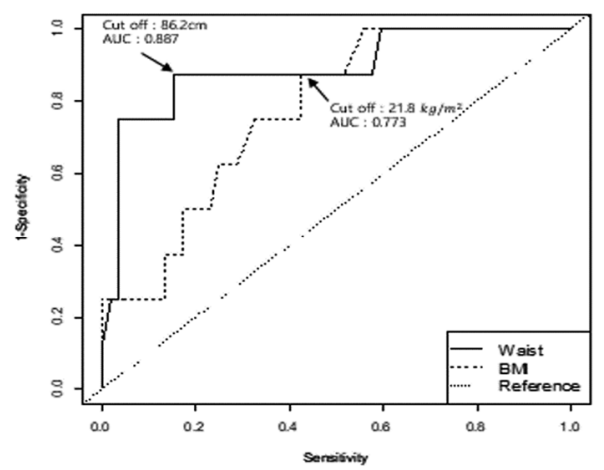

(e) SE type ( 40 years)

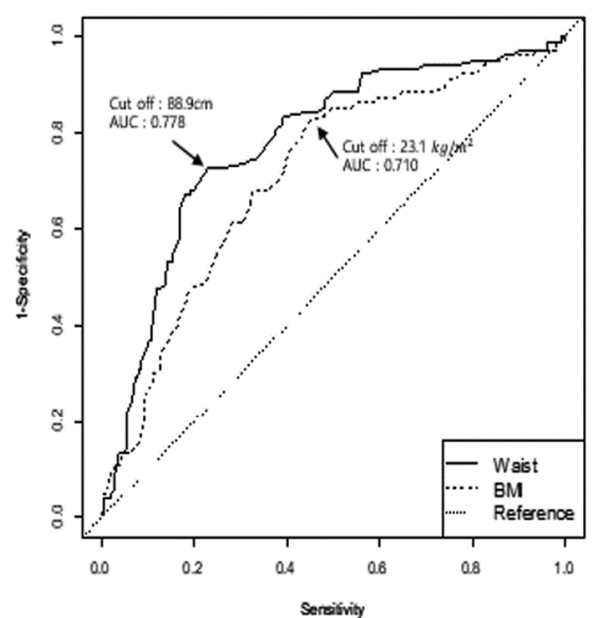

(b) SY type ( $\geq 40$ years)

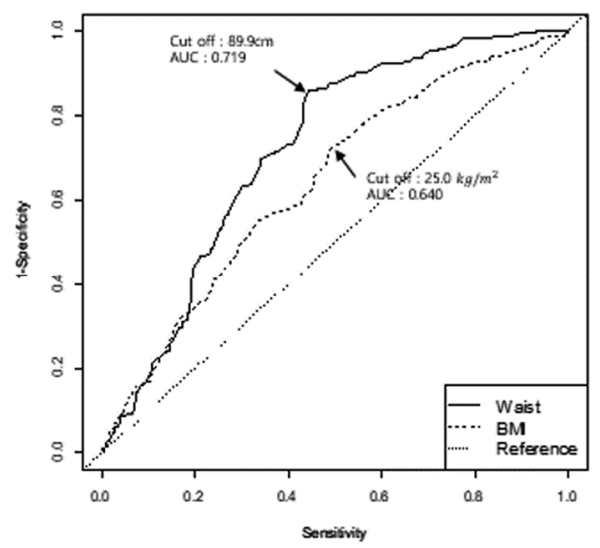

(d) TE type ( $\geq 40$ years)

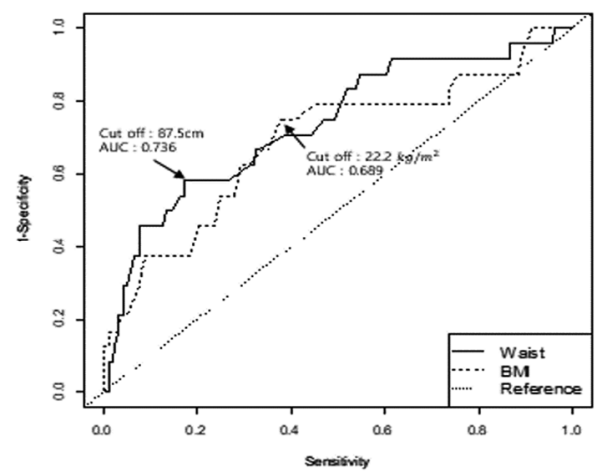

(f) SE type ( $\geq 40$ years)

Fig. 1. The cut-off values for waist circumference (Waist) and body mass index (BMI) according to Sasang constitutional type among men. SY: Soyangin, TE: Taeeumin, SE: Soeumin 


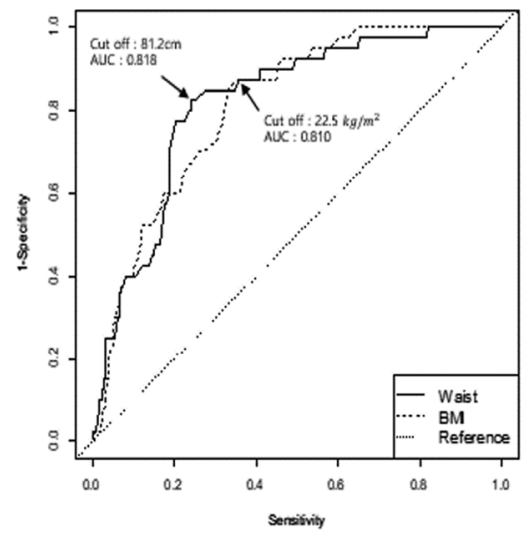

(a) SY type ( $\$ 50$ years)

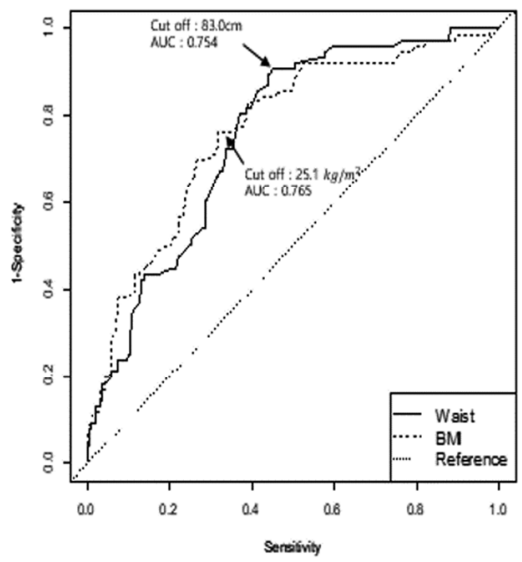

(c) TE type ( $\$ 50$ years)

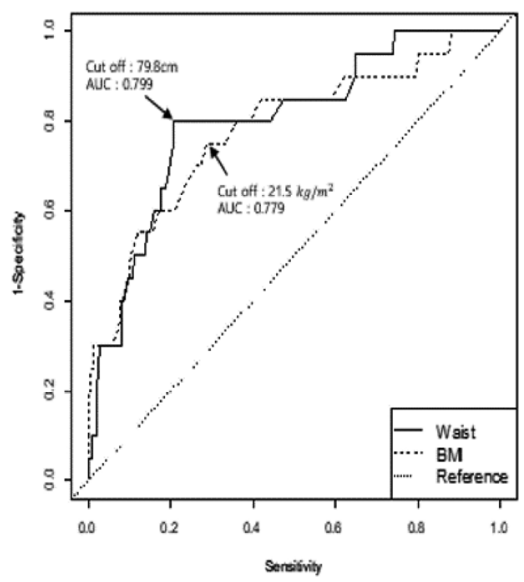

(e)SE type ( 450 years)

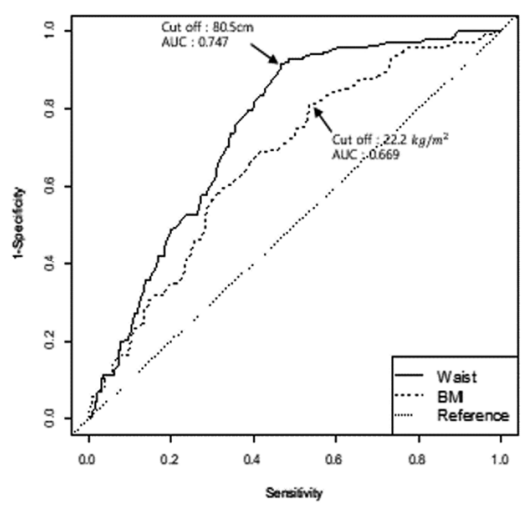

(b) SY type ( $\geq 50$ years)

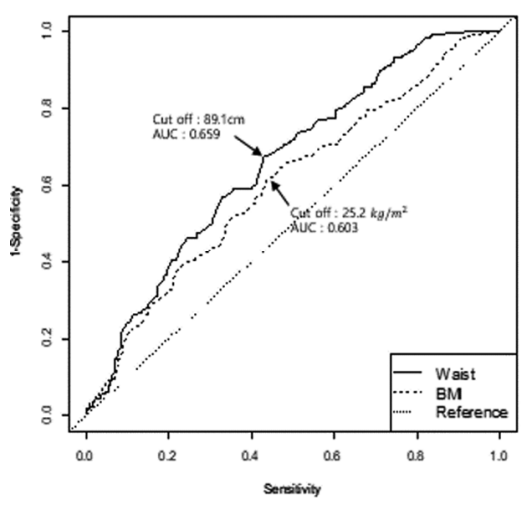

(d) TE type ( $\geq 50$ years)

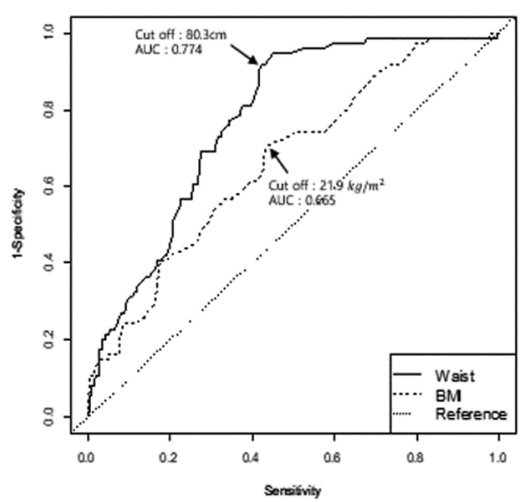

(f) SE type ( $\geq 50$ years)

Fig. 2. The cut-off values for waist circumference (Waist) and body mass index (BMI) according to Sasang constitutional type among women. SY: Soyangin, TE: Taeeumin, SE: Soeumin 
Customized BMI and waist circumference cut-off values are needed to identify metabolic syndrome among South Koreans according to their Sasang constitutional type

Table 4. The BMI and WC cut-off Values, Sensitivities, and Specificities for Predicting MetS according to Sex and SC Type.

\begin{tabular}{|c|c|c|c|c|c|c|c|c|c|}
\hline \multicolumn{5}{|c|}{ Men } & \multicolumn{5}{|c|}{ Women } \\
\hline & & $\begin{array}{c}\text { Cut-off } \\
\left(\mathrm{kg} / \mathrm{m}^{2} \text { or }\right. \\
\mathrm{cm})\end{array}$ & $\begin{array}{c}\text { Sensitivity } \\
(\%)\end{array}$ & $\begin{array}{c}\text { Specificity } \\
(\%)\end{array}$ & & & $\begin{array}{c}\text { Cut-off } \\
\left(\mathrm{kg} / \mathrm{m}^{2} \text { or }\right. \\
\mathrm{cm})\end{array}$ & $\begin{array}{c}\text { Sensitivity } \\
(\%)\end{array}$ & $\begin{array}{c}\text { Specificity } \\
(\%)\end{array}$ \\
\hline \multirow{2}{*}{$\begin{array}{c}\text { SY type } \\
(<40 \text { years })\end{array}$} & BMI & 25.9 & 57.1 & 87.2 & \multirow{2}{*}{$\begin{array}{c}\text { SY type } \\
(<50 \text { years })\end{array}$} & BMI & 22.5 & 87.5 & 64.5 \\
\hline & WC & 89.9 & 78.6 & 87.2 & & WC & 81.2 & 82.5 & 75.7 \\
\hline \multirow{2}{*}{$\begin{array}{c}\text { SY type } \\
(\geq 40 \text { years })\end{array}$} & BMI & 23.1 & 82.5 & 54.8 & \multirow{2}{*}{$\begin{array}{c}\text { SY type } \\
(\geq 50 \text { years })\end{array}$} & BMI & 22.2 & 80.0 & 46.4 \\
\hline & WC & 88.9 & 72.8 & 77.2 & & WC & 80.5 & 91.4 & 53.6 \\
\hline \multirow{2}{*}{$\begin{array}{c}\text { TE type } \\
(<40 \text { years })\end{array}$} & BMI & 25.5 & 76.9 & 56.8 & \multirow{2}{*}{$\begin{array}{c}\text { TE type } \\
(<50 \text { years })\end{array}$} & BMI & 25.1 & 76.3 & 68.2 \\
\hline & WC & 90.5 & 84.6 & 68.2 & & WC & 83.0 & 90.8 & 55.0 \\
\hline \multirow{2}{*}{$\begin{array}{c}\text { TE type } \\
(\geq 40 \text { years })\end{array}$} & BMI & 25.0 & 72.2 & 50.9 & \multirow{2}{*}{$\begin{array}{c}\text { TE type } \\
(\geq 50 \text { years })\end{array}$} & BMI & 25.2 & 61.9 & 56.1 \\
\hline & WC & 89.9 & 86.1 & 55.5 & & WC & 89.1 & 67.8 & 56.6 \\
\hline \multirow{2}{*}{$\begin{array}{c}\text { SE type } \\
(<40 \text { years })\end{array}$} & BMI & 21.8 & 87.5 & 57.7 & \multirow{2}{*}{$\begin{array}{c}\text { SE type } \\
(<50 \text { years })\end{array}$} & BMI & 21.5 & 75.0 & 71.4 \\
\hline & WC & 86.2 & 87.5 & 84.6 & & WC & 79.8 & 80.0 & 79.0 \\
\hline \multirow{2}{*}{$\begin{array}{c}\text { SE type } \\
(\geq 40 \text { years) }\end{array}$} & BMI & 22.2 & 75.0 & 62.2 & \multirow{2}{*}{$\begin{array}{c}\text { SE type } \\
(\geq 50 \text { years })\end{array}$} & BMI & 21.9 & 70.3 & 56.6 \\
\hline & WC & 87.5 & 58.3 & 82.7 & & WC & 80.3 & 91.9 & 57.7 \\
\hline
\end{tabular}

BMI: body mass index, WC: waist circumference, MetS: metabolic syndrome, SY, Soyangin; TE, Taeeumin; SE, Soeumin.

\section{Discussion}

Recent studies of Western and traditional medicine have increasingly focused on personalized physical and genetic evaluations to predict the development of MetS ${ }^{16), 26), 27)}$. Thus, the present study aimed to determine SC type-specific cut-off values for BMI and WC to predict the development of MetS. Furthermore, we assumed that aging-related physical changes could influence these cut-off values, and performed age- and sex-based analyses to determine more accurate cut-off values. The age-based analyses were performed using a cut-off age of 40 years for men (i.e., the approximate onset of andropause) $)^{25)}$ and a cut-off age of 50 years form women (i.e., the approximate onset of menopause) $)^{24)}$.

Groups with higher anthropometric values are generally thought to have a higher risk of MetS, compared to groups with lower values. For example, BMI has the highest ORs among TE-type women and WC has the highest ORs among non-TE-type women, while WC has the highest ORs in both TE-type and non-TE-type men. These results indicate that the predictors of MetS can vary according to SC type, and although WC is a good general predictor, BMI is superior when evaluating TE-type women". Furthermore, one Korean study has also suggested that the appropriate WC cut-off values might be $90 \mathrm{~cm}$ for men and $85 \mathrm{~cm}$ for women ${ }^{28)}$. Although BMI is not a MetS component, it is a convenient and applicable index. Thus, we identified SC type-specific cut-off values for $\mathrm{WC}$ and $\mathrm{BMI}$ according to age and sex group.

The present study revealed that, among men, the BMI cut-off values were $25.9 \mathrm{~kg} / \mathrm{m}^{2}$ for the SY type and $25.5 \mathrm{~kg} / \mathrm{m}^{2}$ for the TE type, which indicates that the standard cut-off $\left(25 \mathrm{~kg} / \mathrm{m}^{2}\right)$ could be acceptable for these SC types. However, the cut-off value for $<40$-year-old men with the SE type was $21.8 \mathrm{~kg} / \mathrm{m}^{2}$, which might indicate that the cut-off for this group should be lowered to $22 \mathrm{~kg} / \mathrm{m}^{2}$. Furthermore, at ages of $\geq 40$ years, the cut-off values were $23.1 \mathrm{~kg} / \mathrm{m}^{2}$ for the SY type, $25.0 \mathrm{~kg} / \mathrm{m}^{2}$ for the TE type, and 22.2 $\mathrm{kg} / \mathrm{m}^{2}$ for the SE type, which may indicate that 23 $\mathrm{kg} / \mathrm{m}^{2}$ is a more appropriate cut-off value for older men with the SY and SE types. The WC cut-off values 
among <40-year-old men were $89.9 \mathrm{~cm}$ for the SY type, $90.5 \mathrm{~cm}$ for the TE type, and $86.2 \mathrm{~cm}$ for the SE type, which may indicate that $90 \mathrm{~cm}$ is appropriate for the SY and TE types, although the cut-off should likely be lowered to $87 \mathrm{~cm}$ for $<40$-year-old men with the SE type. At ages of $\geq 40$ years, the cut-off values were $88.9 \mathrm{~cm}$ for the SY type, $89.9 \mathrm{~cm}$ for the TE type, and $87.5 \mathrm{~cm}$ for the SE type, which also indicates that the cut-off value for $\geq 40$-year-old men with the SE type should be lowered to $88 \mathrm{~cm}$.

Among <50-year-old women, the BMI cut-off values were $22.5 \mathrm{~kg} / \mathrm{m}^{2}$ for the SY type, $25.1 \mathrm{~kg} / \mathrm{m}^{2}$ for the TE type, and $21.5 \mathrm{~kg} / \mathrm{m}^{2}$ for the SE type. Thus, the cut-offs for the SY and SE types should be lowered to $23 \mathrm{~kg} / \mathrm{m}^{2}$. Among $\geq 50$-year-old women, the cut-off values were $22.2 \mathrm{~kg} / \mathrm{m}^{2}$ for the SY type, $25.2 \mathrm{~kg} / \mathrm{m}^{2}$ for the TE type, and $21.9 \mathrm{~kg} / \mathrm{m}^{2}$ for the SE type, which indicates that the cut-off values for the SY and SE types should also be lowered to $23 \mathrm{~kg} / \mathrm{m}^{2}$. Among the $<50$-year-old women, the WC cut-off values were 81.2 $\mathrm{cm}$ for the SY type, $83.0 \mathrm{~cm}$ for the TE type, and $79.8 \mathrm{~cm}$ for the SE type, which generally agree with the $80-\mathrm{cm}$ cut-off value from the Asian-Pacific guidelines. Similarly, the cut-off values among $\geq$ 50 -year-old women were $80.5 \mathrm{~cm}$ for the SY type, $89.1 \mathrm{~cm}$ for the TE type, and $80.3 \mathrm{~cm}$ for the SE type, which indicates that the cut-off value from the Asian-Pacific guideline is appropriate for the SY and SE types.

Interestingly, the WC cut-off value for the TE type was relatively high $(89.1 \mathrm{~cm})$, which indicates that women with the TE type became relatively obese as they experienced menopause. This conclusion is supported by the fact that the mean WC value among all $\geq 50$-year-old women was $86.94 \pm 9.22 \mathrm{~cm}$, compared to $79.36 \pm 8.44 \mathrm{~cm}$ among <50-year-old women. In addition, older women had a significantly high rate of MetS ( $\geq 50$ years: $47.7 \%$ vs. $<50$ years: $14.8 \%$ ), and older women with the TE type had the highest rate of MetS among all SC types (Table 2). In this context, the TE type seems to increase susceptibility to obesity because of a sensitivity to energy intake, based on an imbalance toward preserving energy, and physical differences are observed for each of the SC types $^{29)]}$. Furthermore, a previous study revealed that the prevalence of MetS was $56.3 \%, 49.1 \%, 27.4 \%$, and $26.4 \%$ among the TE-type men, TE-type women, non-TE-type men, and non-TE-type women, respectively ${ }^{9}$. Moreover, the TE type is prone to obesity $^{30)}$ and recent studies have revealed that the TE type is a risk factor for chronic diseases ${ }^{18}$, with TE-type women being prone to develop MetS as they experience menopause. Therefore, these women require careful monitoring and evaluation, and our WC cut-off value $(89.1 \mathrm{~cm})$ requires careful consideration in this group.

To the best of our knowledge, this is the first study to identify BMI and WC cut-off values for predicting MetS according to SC type, sex, and age group. One previous study has examined cut-off values according to SC type, and reported cut-off values for WC among TE-type men $(89.9 \mathrm{~cm})$, non-TE-type men $(88.6 \mathrm{~cm})$, and non-TE-type women $(80.6 \mathrm{~cm})$, as well as a BMI cut-off value of $25.2 \mathrm{~kg} / \mathrm{m}^{2}$ among TE-type women". However, the findings of the present study are more comprehensive, and may be useful for developing personalized management strategies. Furthermore, we attempted to increase the reliability of our findings by examining data from a Korean national database, which had implemented methods to minimize measurement errors using education and standard operating procedures.

The present study has several limitations. First, the study used a cross-sectional design, and the associations that we observed may not be causal. Second, body shape can be related to environmental factors, such as exercise and eating habits, although we were not 
able to evaluate these factors. Therefore, larger prospective studies are needed to validate our findings and determine the abilities of the WC and BMI cut-off values for predicting the development of MetS among individuals with each SC type.

\section{Conclusion}

The present study revealed that the WC and BMI cut-off values should likely be lowered for some groups of men and women with the SY and SE types. A higher WC cut-off value may be appropriate for older women with the TE type. The use of appropriate BMI and WC cut-off values may help more accurately predict the development of MetS according to SC type.

\section{Acknowledgements}

This research was supported by a "Establishment of Korean Medicine Genome and Epidemiology Infrastructure" grant from the Korea Institution of Oriental Medicine (K17091). The data supporting this study's findings are available from the Korean Medicine Data Center (http://kdc.kiom.re.kr), although they are not freely available. Researchers who fulfill the criteria for access to confidential data can apply for access to the Korean Medicine Data Center.

This research was funded by Sangji University 2016.

\section{Conflicts of Interest}

The authors declare that there are no conflicts of interest regarding the publication of this article.

\section{References}

1. Lakka HM, Laaksonen DE, Lakka TA, Niskanen LK, Kumpusalo E, Tuomilehto $\mathrm{J}$ and et al. The metabolic syndrome and total and cardiovascular disease mortality in middle-aged men. Journal of the American Medical Association. 2002;288(21): 2709-2716.

2. Obunai K, Jani S, Dangas GD. Cardiovascular morbidity and mortality of the metabolic syndrome. Medical Clinics of North America. 2017;91:1169-1184.

3. Gami AS, Witt BJ, Howard DE, Erwin PJ, Gami LA, Somers VK, et al. Metabolic syndrome and risk of incident cardiovascular events and death: a systematic review and meta-analysis of longitudinal studies. Journal of the American College of Cardiology. 2007;49(4):403-414.

4. Wang F, Wu S, Song Y, Tang X, Marshall R, Liang $\mathrm{M}$, et al. Waist circumference, body mass index and waist to hip ratio for prediction of the metabolic syndrome in Chinese. Nutrition, Metabolism and Cardiovascular Diseases. 2009;19(8):542-547.

5. Katz EG, Stevens J, Truesdale KP, Cai J, Adair LS, North KE. Hip circumference and incident metabolic risk factors in Chinese men and women: the People's Republic of China Study. Metabolic Syndrome and Related Disorders. 2011;9(1):55-62.

6. Haghighatdoost F, Amini M, Feizi A, Iraj B. Are body mass index and waist circumference significant predictors of diabetes and prediabetes risk: Results from a population based cohort study. World Journal of Diabetes. 2017;8(7):365-373.

7. Kim BS, Bae HS, Lim CY, Kim MJ, Seo JG, Kim JY, et al. Comparison of gut microbiota between Sasang constitutions. Evidence-Based Complementary and Alternative Medicine. 2013;171643. Epub 2013

8. Lee JM [Choi SH, translator]. Longevity and life preservation in Eastern medicine. Seoul:Kyung Hee University Press. 2009.

9. Jang E, Baek Y, Park K, Lee S. Can anthropometric 
risk factors important in Sasang constitution be used to detect metabolic syndrome? European Journal of Integrative Medicine. 2014;6(1):82-89.

10. Jang ES, Yoo JH, Baek YW, Kim HS, Kim JY, Lee SW. The association between symptom evaluation index and health state according to Sasang constitution in women. Journal of Sasang Constitutional Medicine. 2009:21(3):107-121.

11. Baek YW, Yoo JH, Kim HS, Jang ES. The association between symptom evaluation index and quality of life according to Sasang constitution in men. Journal of Sasang Constitutional Medicine. 2010:22(2):48-59.

12. Baek YW, Kim HS, Lee SW, Jang ES. The association between Sasang constitution and quality of life according to the personality pattern. Journal of Sasang Constitutional Medicine. 2011:23(3):330-339.

13. Chae H, Lyoo IK, Lee SJ, Cho S, Bae H, Hong $\mathrm{M}$, et al.. An alternative way to individualized medicine: psychological and physical traits of Sasang Typology. The Journal of Alternative \& Complementary Medicine. 2003;9(4):519-528.

14. Kim JY, Pham DD. Sasang constitutional medicine as a holistic tailored medicine. Evidence-Based Complementary and Alternative Medicine. 2009; Suppl 1:11-19.

15. Lee J, Lee E, Yoo J, Kim Y, Koh B. The Sasang constitutional types can act as a risk factor for hypertension. Clinical and Experimental Hypertension.2011;33(8):525-532.

16. Lee TG, Lee SK, Choe BK, Song IB. A study on the prevalences of chronic diseases according to Sasang constitution at a health examination center. Journal of Sasang Constitutional Medicine. 2005;17(2):32-45.

17. Lee TG, Koh B, Lee S. Sasang constitution as a risk factor for diabetes mellitus: a cross-sectional study. Evidence-Based Complementary and
Alternative Medicine. 2009;suppl 1:99-103.

18. Jang E, Baek Y, Park K, Lee S. Could the Sasang constitution itself be a risk factor of abdominal obesity? BMC Complementary and Alternative Medicine. 2013;13:72.

19. Jang E, Kim JY, Lee H, Kim H, Baek Y, Lee S. A study on the reliability of Sasang constitutional body trunk measurement. Evidence-Based Complementary and Alternative Medicine. 2012; 604842. Epub 2011.

20. Song KH, Yu SG, Cha S, Kim JY. Association of the apolipoprotein A5 gene $-1131 \mathrm{~T}>\mathrm{C}$ polymorphism with serum lipids in Korean subjects: impact of Sasang constitution. EvidenceBased Complementary and Alternative Medicine. 2012;598394. Epub 2011.

21. Korea Institute of Oriental Medicine. Development of diagnostic and herbal drug system based on traditional constitutional Korean medicine. Daejeon, Korea: Korea Institute of Oriental Medicine, 2007.

22. Grundy SM, Brewer HB Jr, Cleeman JI, Smith SC Jr, Lenfant C. Definition of metabolic syndrome report of the National Heart, Lung, and Blood Institute/American Heart Association conference on scientific issues related to definition. Circulation. 2004;109(3):433-438.

23. World Health Organization. The Asia-Pacific perspective: redefining obesity and its treatment. Geneva, Switzerland: World Health Organization, 2000.

24. Cooper GS, Sandler DP. Age at natural menopause and mortality. Annals of Epidemiology. 1998; 8(4):229-235.

25. Samipoor F, Pakseresht S, Rezasoltani P, Kazemnajad LE. Awareness and experience of andropause symptoms in men referring to health centers: a cross-sectional study in Iran. The Aging Male. 2017;20(3):153-160. 
26. Wu Y, Cun Y, Dong J, Shao J, Luo S, Nie S, et al. Polymorphisms in PRARD, PPARG and APM1 associated with four types of traditional Chinese medicine constitutions. Journal of Genetics and Genomics. 2010;37(6):371-379.

27. Sumantran VN, Tillu G. Cancer, inflammation, and insights from Ayurveda. Evidence-Based Complementary and Alternative Medicine. 2012;306346. Epub 2012

28. Lee SY, Park HS, Kim DJ, Han JH, Kim SM, Cho GJ, et al. Appropriate waist circumference cutoff points for central obesity in Korean adults. Diabetes Research and Clinical Practice. 2007;75(1):72-80.

29. Cha S, Koo I, Park BL, Jeong S, Choi SM, Kim $\mathrm{KS}$, et al. Genetic effects of FTO and MC4R polymorphisms on body mass in constitutional types. Evidence-Based Complementary and Alternative Medicine. 2011;106390. Epub 2011.

30. Chae H, Lee S, Park SH, Jang E, Lee SJ. Development and validation of a personality assessment instrument for traditional Korean medicine: Sasang personality questionnaire. Evidence-Based Complementary and Alternative Medicine. 2012;657013. Epub 2012.

\section{ORCID}

Jun-Sang Yu: https://orcid.org/0000-0003-0190-0193

Younghwa Baek: https://orcid.org/0000-0002-1827-1701

Daesung Hyun: http://orcid.org/0000-0002-3911-3913

Sei-Jin Chang: http://orcid.org/0000-0001-9347-3592 